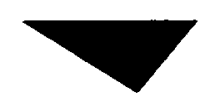

\title{
Do realismo à visibilidade. Efeitos de realidade e ficção na representação audiovisual
}

\author{
Jose Luis Fecé \\ Universidade Autônomade Bancelona
}

"Ce n'est pas une image juste, c'est juste une image" Jean-Luc Godard

A convergência entre os complexos sistemas de transmissão, armazenagem e processamento de informaçāo de imagens fará florescer, segundo os discursos mais otimistas, uma "nova sociedade da comunicação", uma espécie de irmandade universal que nos fará a todos mais iguais, mais conhecedores. Até os pesquisadores e analistas mais otimistas reconhecem que a "democratização" prometida, essa nova utopia, corre o risco de se transformar em homogeneização. A chamada "globalização" supõe, entre outras coisas, a perda de referências espaciais e temporais. Como assinalou recentemente Paul Virilio, "pela primeira vez o jogo da história vai se dar em um tempo único: o tempo mundial. A história tem se desenvolvido, até agora, em um tempo local, em espaços locais, das regiões, das naçōes. Agora, de alguma forma, a mundialização e a virtualização prefiguram um novo tipo de tirania" ${ }^{1}$. Para o pensador francês, a partir de agora a história vai se construir em um perpétuo presente. Diante desta situação superficialmente descrita cabe se perguntar, por certo entre muitas outras coisas, que papel tem o audiovisual em sua pretensão de refletir a realidade e fazê-lo de um modo honesto. Em uma época em que as instituições dominantes (especialmente as grande corporaçōes de comunicação) acabaram de impor uma equação já utilizada pelos pintores e teóricos do Quat, rocento, Ver $=$ Crer, se faz imprescindivel refletir sobre as 
questōes referentes à representação da realidade, a pretendida "transparência" da imagem em movimento, especialmente quando, graças à transmissão direta, o espectador pode "assistir", teoricamente como testemunha e sem mediação alguma. a qualquer acontecimento que se produza no planeta.

Contudo, no circuito ilimitado da informação-mercadoria, qualquer coisa representada tende a trocar de signo; verdadeiro/ falso, real/virtual, presente/futuro; a inversão de signos se generaliza ${ }^{2}$. Em um mundo onde qualquer prova pode ser combatida com outra prova inversa, a evidência ou transparência não é mais que um engano ${ }^{3}$. Faz poucos anos, durante um debate no Festival Cinéma du Réel, o cineasta francês Raymond Depardon advogava pelo abandono das técnicas do cinéma direct. Não só têm sido adotadas pelo documentário e pela reportagem televisiva, como também pelos reality shows, incluindo o pornô amateur. Na presente exposição pretendo realizar uma pequena aproximação da problemática da representação da realidade, centrando-me no documentário cinematográfico e na reportagem televisiva. Em lugar de falar de "realismo" ou "realidade", falarei de efeitos de realidade, interessando-me pela constituição desses efeitos nos primeiros filmes dos irmãos Lumière. Os primeiros filmes já instituíam um espaço virtual, o contracampo e, de certo modo, o fora do campo, elementos ausentes nas reportagens televisivas e nas transmissōes diretas. A ausência de contracampo é um dos fatores que impedem a percepção consciente da representação; até diante do filme mais "realista", o espectador sabe que está vendo um filme, sabe que entre o representado e sua representação existe uma mediação, um ponto de vista. Ao contrário, o discurso televisivo, especialmente nas retransmissões diretas, pretende ocultar essa mediação: o representado é percebido de modo imediato, como se o espectador fosse testemunha do acontecimento. Poderíamos dizer que na televisão, de modo diferente do que no cinema, o espectador não acredita estar diante da verdade da representação, mas sim diante da "verdade" do representado. Aparentemente, o discurso assegurador-informativo da comunicação não apresenta ao espectador realidades mediadas, e sim "verdades indiscutíveis". E o espectador não tem acesso ao mundo através da experiência ou do conhecimento, mas por meio dessas representações que aparecem como verdadeiras. 


\section{Imagens sem contracampo}

Não faz muito se comemorava em todo o mundo o centenário do cinema. Boa ocasião para comprovar como o discurso mediático se apropriava de um meio que, segundo alguns historiadores, nasceu sob a sindrome do doutor Frankenstein ${ }^{4}$ : como um novo passo - talvez o definitivo - até a (re)criação da realidade. De certo modo, a celebração do centenário do cinema se converteu em uma apoteose do presente; ao fim e ao cabo, o invento dos irmãos Lumière apareceu como 0 antepassado de nossas modernas câmaras de televisão. Ao longo de 1995, a historiografia positivista encontrou todo tipo de facilidades para demonstrar o nexo de união entre o Cinematógrafo Lumière e as chamadas novas tecnologias: o desejo do homem de reproduzir a realidade, de lograr a realização de uma perfeita ilusão do mundo perceptivo. O cinema nasceu na forma documental. É possivel. Contudo, as imagens de Lumière estão longe de serem simples recriações da realidade.

Narra a lenda que os espectadores das primeiras projeções dos irmãos Lumière fugiram apavorados ante a locomotiva que "avançava" até eles. Esta história é fascinante, mas não existe prova documental que a certifique. As crônicas da época falam, não obstante, da grande quantidade de "personagens ou grupos animados" que apareciam naqueles filmes; do estremecimento das folhas sob a ação do vento e inclusive de "uns ferreiros dedicados a seu ofício que pareciam de carne e osso. Via-se 'incandescer' ao fogo as barras de ferro". Houve também um cronista que chegou a ver "cenas reproduzidas com as cores da vida".

Em 1966, na inauguração de uma retrospectiva Lumière na Cinemateca de Paris, Jean-Luc Godard pronunciou uma de suas provocativas sentenças: “O que interessava a Méliès era o ordinário no extraordinário, e a Lumière o extraordinário no ordinário. Louis Lumière, através dos impressionistas, era, pois, descendente de Flaubert e também de Stendhal, cujo espelho passeou ao largo dos caminhos". Dito de outra forma, Godard não considerava Lumière como o inventor de um instrumento capaz de reproduzir a realidade, e sim como "o último pintor impressionista", "um contemporâneo de Proust"s. Lumière deixa de ser um inventor, um técnico e passa a ser um artista, criador 
de elementos extraordinários: os efeitos de realidade.

Como boa parte das pinturas do século XIX, as imagens de Lumière seduziam por suas minúcias, por seu poder de "computar" imaginariamente o real e reduzi-lo ao indefinidamente acumulável, por sua capacidade de captar uma grande quantidade de detalhes. E precisamente essas minucias ultrapassam a realidade. Outro efeito de realidade: a qualidade; a perfeição com que se percebe o vento agitando as folhas das árvores, 0 fumo, os reflexos e, sobretudo, o movimento. Aparentemente e ressalvando as distâncias, tudo aquilo que seduz os espectadores das imagens de Lumière segue impressionando os consumidores de "novas" imagens. Vejamos, contudo, algumas diferenças.

Recordemos que a imagem de Lumière, por exemplo em L'arrivée d'un train en gare, supõe, entre outras coisas, a inversão do sistema perspectivo herdado do Renascimento: a atenção do observador, seu olhar, não se dirige da borda do quadro até o ponto de fuga, e sim o contrário. As imagens de Lumière criam um novo espaço, um espaço que ultrapassa os limites da tela, o espaço da filmagem. Assim, pois, o enquadramento das imagens de Lumière institui uma relação com a posição da câmara e a tela se converte em um espaço ficcional situado entre outros dois espaços: o do filmado e aquele ocupado pelo cameraman. $O$ enquadramento dos filmes produzidos pela Maison Lumière institui um ponto de vista. Na medida em que o cinematógrafo evoluía até a constituição do que Noël Burch denomina Modo de Representação Institucional (MRI) ${ }^{6}$, o fora do quadro (como lugar da filmagem, lugar ocupado pelo cameraman) se transforma em fora do campo. $O$ fora do campo como lugar do potencial, do virtual, mas também da desaparição e do desvanecimento: lugar do futuro e do passado muito antes de ser do presente. Bastante se sabe que no cinema anterior a 1915 o plano era um verdadeiro quadro cênico, isto é, uma entidade auto-suficiente; para muitos, um "pedaço de realidade"; somente com a consolidação do MRI é que o plano "desaparecerá", dando lugar a um espaço de representação. Trata-se agora de um espaço da ficção, oposto ao espaço real.

Tomemos um exemplo: o Arroseur arrosé de Lumière. Em um só plano se representa uma ação completa; um homem rega 
tranqüilamente seu jardim, aparece um jovem que pisa a mangueira impedindo a passagem da água. Quando o jardineiro olha para o final da mangueira, o trocista tira o pé de cima dela e a água flui de novo, ensopando o nosso amigo bonachão. No filme ocorre, além disso, algo fantástico: o irado jardineiro empreende a perseguição ao trocista; ambos desaparecem pela esquerda do enquadramento para reaparecer segundos mais tarde (também pela esquerda) e, ante os olhos do público, o jovem brincalhão recebe o merecido. $O$ extraordinário é que parte da ação (perseguição ao trocista) transcorre fora do alcance da vista do espectador; longe de imitar ou reproduzir a realidade, a imagem de Lumière institui um espaço ficcional que inclusive pode se prolongar além da própria imagem. Insistamos nisso: a imagem de Lumière institui um campo visual e, com ele, um fora de campo, um "mais além" da imagem. E essa é a imagem do cinema, uma imagem "imperfeita"; sua presença impõe igualmente uma ausência.

O que interessa destacar, depois deste brevíssimo passeio pelo chamado cinema primitivo, é que os efeitos de realidade coexistem com efeitos de ficção e que estes têm que ver com esse espaço virtual, não visivel ainda que presente na mente do espectador, que constitui o fora do campo. Dito de outro modo, o cinema não funciona completamente sobre a absoluta visibilidade, sobre a evidência da imagem. Precisamente nestes momentos em que a "sociedade da imagem" aparece como uma realidade inapelável, tem sentido, em minha opinião, recuperar o discurso de André Bazin sobre as relações entre a imagem e a realidade.

Recorda Bazin que o ato de filmar, na medida em que é uma atividade humana, supōe uma subjetividade, uma interpretação (por exemplo, através do enquadramento) da realidade. Desse modo, Bazin contesta as proposições dos antigos teóricos do cinema que viam na montagem o principal ato organizador. De acordo com as proposições bazinianas, Eric Rohmer, em um de seus textos mais importantes (assinado com seu verdadeiro nome, Maurice Shérer), Le cinéma art de l'espace, substitui a noção de realidade pela de espaço. Para Rohmer a essência do cinema não reside em uma hipotética relação estática com a realidade, e sim na construção de um espaço virtual. Tanto Bazin quanto Rohmer distinguem a objetividade mecânica (da câmara) do realismo 
psicológico. A "realidade" não se faz na película, mas na consciência do espectador e do cineasta, vale dizer, do sujeito. A semelhança entre o universo filmado e o mundo real, produzida pelo mecanismo da câmara cinematográfica, outorga credibilidade a esse espaço virtual, distinguindo-se este da realidade filmada, sem atraiçoá-la ainda que apoiando-se nela. Pareceu-me oportuna a referência às posições bazinianas, posto que recordam, diferentemente dos discursos dominantes sobre a imagem, que a noção de realismo não tem uma base tecnológica, e sim psicológica, social e histórica.

\section{Do realismo à visibilidade}

Evidentemente, a problemática do realismo é muito mais ampla e não pode afastar aquelas contribuições que se interessaram pelas narrativas ${ }^{7}$; por economia centrei-me em contribuições interessadas na complexa relação - hipoteticamente de contigüidade - entre a câmara (fotográfica, cinematográfica ou de vídeo) e o real. Das posições de Bazin, Rohmer ou, por exemplo, de Christian Metz ${ }^{8}$, se deduz que a idéia de ver o cinema como um meio que pode facilitar um discurso descritivo objetivo do mundo é, simplesmente, uma ingenuidade. Apesar de que toda imagem (fotográfica, cinematográfica ou videográfica) desvela uma realidade preexistente capturada pela câmara, manifesta também a presença de um pensamento, de uma subjetividade. Acabamos de ver como os filmes de Lumière, que em algumas ocasiões foram erigidos em paradigma do realismo cinematográfico, revelam uma subjetividade que se manifesta por meio do enquadramento e a instituição de um campo e um fora de campo (como no caso de L'arroseur arrosé).

Tampouco podemos esquecer que os realismos não só estabelecem uma questão formal - como representar a realidade -, como também uma atitude ética que consiste, grosso modo, na busca de um ideal de verdade. Todavia veremos como esse ideal de verdade - como por exemplo no Neo-realismo italiano ou no Cinema Novo brasileiro - não tem nada que ver com essa forma de ilusionismo que procura fazer crer ao espectador que é possível conseguir uma suposta transparência da representação. Ao contrário, movimentos como os mencionados questionam a plenitude, a evidência das imagens; o cinema moderno propõe 
uma interpretação entre o real e a ficção, uma subversão da realidade e também uma erosão das convenções ficcionais. Crítica da transparência mas também busca da possível transformação da sociedade. É evidente que o realismo cinematográfico tem pouco que ver com o regime da visibilidade, o qual supõe um hipotético acesso ao mundo graças ao poder da imagem e da transmissão ao vivo. A visibilidade, ou, se se prefere, o realismo mediático, pressupõe a transparência do mundo; coloca o espectador na situação de "testemunho", como se a simples presença do sujeito ante um acontecimento determinado bastasse para compreendê-lo e pretendesse a insta uração de uma confiança absoluta na tecnologia. Não obstante, realismo e visibilidade compartilham algumas características formais, alguns desses efeitos de realidade de que falamos há pouco. Vejamos o exemplo do cinéma direct ${ }^{9}$.

Esta corrente cinematográfica, que apareceu nos anos 60 e se consolidou durante os anos 70 e parte dos 80 , aparece hoje como o involuntário antecedente desse "realismo" mediático fundamentado na máxima visibilidade do mundo. Segundo Gilles Marsolais, "o cinéma direct designa um tipo de cinema que capta de modo direto ('sobre o terreno') a palavra e o gesto graças a um material (a câmara e o magnetófono) ligeiro, vale dizer, um cinema que estabelece um contato 'direto' com o homem, que procura se conectar da melhor maneira possível com a realidade (...) este tipo de cinema não pretende mostrar a realidade em uma bandeja de prata, e sim delinear o problema da verdade no nível das relações humanas. Antes de tudo, o cinéma direct é um cinema da comunicação" ${ }^{10}$. Para o cinéma direct, já não é necessá. rio falar ou comentar as imagens registradas pela câmara. A realidade se mostra e se enuncia. Já não é necessário transformar o mundo, basta vê-lo, observá-lo. Desse modo, todo discurso ideológico, inclusive o discurso propagandístico, deveria ser transbordado. É preciso desembaraçar-se de toda concepção apriorística de uma realidade determinada, já que este tipo de representação pode nos impedir de ver, de escutar; em uma palavra, descobrir o mundo tal como ele é. O cinéma direct pretende redescobrir uma virgindade do olhar e da audição, e sua máxima poder-se-ia enunciar do seguinte modo: ver para saber. Dessa maneira, já não tem sentido efetuar pesquisas ou investigações anteriores à filmagem; o tempo da filmagem substitui o tempo da investigação 
ou da pesquisa. O cineasta se esforça para impor a presença da câmara a toda uma série de instituições (polícia, empresas, organismos públicos etc.) que iludem a visibilidade (tanto que, com o tempo, acabaram aprendendo a se esforçar para conseguir o seu próprio "visível", a sua própria "evidência"). Se este tipo de cinema pretende combater os juízos prévios e as concepções apriorísticas, reinvindica, talvez inconscientemente, uma sociedade transparente. Por que a sociedade desconfiaria de um cinema que não toma partido e se contenta em restituir tudo aquilo que a câmara registra? Paradoxalmente, o cineasta da evidência, do mesmo modo que o repórter, tende à invisibilidade, às imagens-clichê, uma vez que, conforme dizíamos há pouco, as instituições aprenderam a conseguir a sua própria visibilidade, construindo-a à sua medida. Dito de outro modo, estabeleceram as suas próprias ficções.

\section{$O$ contracampo, questão política}

Alcançado este ponto, podemos nos perguntar, sempre e quando não partimos do fundamento de que a realidade é algo intangível, existente fora de nós, como e em quê os efeitos da realidade produzidos por determinados documentários ou reportagens televisivos reproduzem o estado das coisas, questionam os clichês ou uma visão preestabelecida do mundo. Segundo o cineasta Robert Kramer, "a definição da realidade é uma construção política. O poder consiste na possibilidade de definir o que é real" ${ }^{\prime 1}$. Tivemos ocasião de comprová-lo durante a guerra do Golfo, a mais vista - ali estava a CNN para nos oferecê-la ao vivo - e a mais opaca - posto que as imagens eram selecionadas a partir do Pentágono. Tratava-se de impedir que sucedesse o mesmo que com o Vietnam, uma guerra sem consenso. Do nosso ponto de vista, poderíamos dizer que enquanto a guerra do Golfo foi a guerra do visual (recordemos as imagens do bombardeio de Bagdá, semelhantes às de um video game; os mapas, os diagramas, em definitivo, a máxima visibilidade), a do Vietnam foi a da imagem; imagens de corpos queimados, mutilados, destroçados; corpos que produziram uma memória. Uma guerra sem corpos é uma guerra "limpa". Eliminar a imagem para impedir a memória.

Existe uma grande diferença entre a imagem e o visual; este último seria a verificação ótica de um funcionamento puramente 
técnico. Nesse sentido, o visual é inapelável. Pelo contrário, uma das principais características da imagem é sua insuficiência, sua imperfeição. As imagens dos irmãos Lumière eram "incompletas", inclusive para os primeiros espectadores. Supondo que a lenda da locomotiva seja certa, o suposto perigo se encontrava fora da imagem (hoje diríamos fora do campo ou no contracampo), na mente do espectador. Seguramente os primeiros espectadores não confundiram a imagem da locomotiva com o objeto real; portanto, se de algo tiveram medo não foi desse objeto (real) e sim de sua representação. Em um artigo intitulado Montage obligé, em clara alusão ao famoso texto de Bazin Montage interdit, Serge Daney ${ }^{12}$ afirmava que a imagem, diferentemente do visual, sempre tem lugar na fronteira entre dois campos de força, estando condenada a testemunhar uma certa alteridade: "Qu'il y ait aussi de l'autre, c'est donc ça l'image du cinéma. Et qu'il n'y ait que de l'un, c'est le visuel de la télévision". A imagem, inclusive as imagens de Lumière, institui um espaço imaginário (o contracampo e o fora do campo), um espaço do inesperado, um espaço ao mesmo tempo presente (na mente do espectador) e ausente (da imagem). Seguindo com Daney, a imagem nos obriga a relacioná-la com o outro, "dans l'image, comme dans la démocracie, il y a du jeu et de l'inachevé, une entame ou une béance". Na televisão não existe o contracampo, tão-só imagens que fascinam o espectador por sua pseudo-evidência. Assim, regressando às "imagens" pseudoevidentes da guerra do Golfo, a televisão nos obrigava a ver quando, na realidade, havia pouco para se ver. Provavelmente Baudrillard tenha razão e a guerra do Golfo jamais tenha tido lugar ${ }^{13}$.

\section{A tirania da atualidade e o desa parecimento do tempo histórico}

A televisão mostra o como das coisas, mas dificilmente o por $q u \hat{e}$; sacrifica o universal ao particular, as idéias abstratas a uma realidade reduzida ao visível. Para a televisão não existem os "grandes princípios" nem, certamente, as ideologias; só lhe importa o como das coisas, vale dizer, sua visibilidade imediata. Se há um eixo comum nas mensagens mediáticas, este é o primado da atualidade, a preeminência do presente como mais-valia inicial de qualquer material suscetível de ter interesse comunicativo com o público. Este primado da atualidade significa oferecer uma 
perspectiva presentista da realidade, privilegiando a novidade dos acontecimentos e desmotivando a consciência e a memória históricas.

Aqui, a transmissão televisiva direta tem jogado um papel importante, criando um presente a-histórico, descontextualizado, onde a realidade vem a se confundir com a atualidade. A realidade aparece como um continuum de dados que se superpõem sem outra hierarquia que a ordem cronológica. $O$ presente se configura, então, como um conjunto de temas que substituem outros temas, de personagens, de dados e de fatos que adquirem relevância por sobre o seu interesse objetivo e, em algumas ocasiōes, sem relação alguma com o devenir histórico. Simplesmente seu interesse reside em sua "atualidade". É o momento de recordar a idéia de Paul Virilio segundo a qual as novas tecnologias audiovisuais e da informação vão eliminar o tempo histórico. Como exemplo concreto, tomemos as cada vez mais habituais montagens e seleção de imagens históricas oferecidas como puro simulacro de realidades passadas. Sua suposta evidência faz com que a interpretação histórica seja completamente desnecessária. Anulado o tempo histórico e a interpretação, essas imagens se convertem em um modo de legitimação do presente ou também em uma simples recreação visual distante de qualquer vontade de construir uma memória histórica.

Além disso, o critério de atualidade, a vertigem da comunicação mediática, dificulta a capacidade de assimilação dos conteúdos informativos. Para facilitar a compreensão, para produzir conhecimento, é preciso que o acontecimento se apresente em sua máxima visibilidade, ou seja, que se reduza ao máximo sua complexidade. O objetivo da visibilidade não é o conhecimento, e sim o reconhecimento, o enciclopedismo estéril, no melhor dos casos. E para favorecer esse reconhecimento a imagem deve perder sua complexidade e se aproximar do clichê, do tópico.

\section{A imagem, os tópicos, os prejuizos}

Espero que esta crítica, mais ou menos explícita, à chamada civilizaç̃o da imagem não seja in terpretada como uma mostra a mais de iconofobia, posição que, por outra parte, não constitui nenhuma novidade. Já Platão colocava a imagem ao lado da cópia, do ídolo, do sensível e não do inteligível. Por outro lado, parece 
evidente que a imagem apresenta uma série de "desvantagens" em relação à palavra. Em primeiro lugar, a imagem é sempre afirmativa, não admite a negação, nem a ausência, é presença plena. Em segundo lugar, a imagem se "conjuga" sempre no presente, não traduzindo, pois, as relações de subordinação, de causalidade, de conseqüência. Por último, a imagem é sempre anedótica, particularizante. Para Gilles Deleuze "a imagem não cessa de cair em estado de lugar-comum; porque se insere nos encadeamentos sensoriomotores, porque ela mesma organiza ou induz estes encadeamentos, porque nunca percebemos tudo 0 que há na imagem, porque ela está feita para isso (para que percebamos tudo, para que o tópico nos oculte a imagem...). Civilização da imagem? De fato æe trata de civilização do lugar-comum, onde todos os poderes têm interesse em nos ocultar as imagens, não forçosamente em nos ocultar a mesma coisa e sim em nos ocultar algo na imagem."14

Por um lado, o tópico é consubstancial à imagem e todo ele possui uma rentabilidade econômica e ideológica. Contentar-meei em apontar alguns desses aspectos:

$\star O$ cinema-direto pensou que a câmara podia registrar, concordar diretamente com a realidade. Criou uns efeitos de realidade, em princípio mais convincentes que os do documentário clássico. Com o tempo, determinadas instituiçōes (polícia, exército, serviços do Estado como hospitais, universidades etc.) aprenderam a administrar suas próprias imagens, sua própria visibilidade. Em conseqüência, aprenderam a colocar em cena suas próprias ficçōes.

*Para o discurso mediático a realidade só pode ser visível. Para conhecer, melhor dito, reconhecer um fato, este tem de ser visível. As instuições, os governos, os poderes regulam o acesso ao visível. Por exemplo, recordemos que enquanto as televisões de todo o mundo retransmitiam a suposta revolução romena, os Estados Unidos invadiam o Panamá. Não houve imagens, tam. pouco invasão.

^ Os efeitos de realidade e a transmissão direta contribuíram para criar a ilusão de um mundo transparente, ao qual podemos aceder diretamente, graças à tecnologia. $O$ espectador, como Forrest Gump (Robert Zemeckis, 1994), assiste como testemunho 
aos principais acontecimentos e se converte em protagonista da História. Assim, a História ficaria reduzida ao meramente visivel.

$\star$ Quando falamos da forma pela qual os meios de comunicação se aproximam de uma realidade determinada, nos referimos aos interesses dos grupos de comunicação. Nunca insistimos suficientemente sobre um aspecto muito estudado na imprensa: as rotinas profissionais. De que forma a organização do trabalho jornalístico determina os tipos de imagens de um dado acontecimento? Até que ponto a instituição periodística impõe imagens preestabelecidas, prefixadas, do mundo?

Assim, pois, a imagem não cessa de cair no estado de tópico... Por outro lado, recorda Deleuze, "a imagem intenta permanentemente perfurar o tópico, sair dele (...) Às vezes se necessita restaurar as partes perdidas, reencontrar tudo o que não se vê na imagem, tudo o que se subtrai dela para fazê-la 'interessante'. Mas às vezes, pelo contrário, há que fazer furos, introduzir vazios e espacos brancos, rarefazer a imagem, suprimir dela muitas coisas que se lhe haviam incorporado para nos fazer crer que se via tudo. Há que dividir ou construir o vazio para reencontrar o inteiro" ${ }^{15}$.

\section{Interpenetração entre realidade e ficção}

Os discursos sobre a visibilidade, a transparência da imagem e sobre a confiança na tecnologia deveriam se contrastar com outros que questionassem a plenitude, a evidência das imagens. As ficções do visível proporcionam ao espectador a ilusão de que é possível ver tudo, quando na realidade, já dissemos, as instituições selecionam e autorizam tudo aquilo suscetível de ser mostrado. Ver não supõe necessariamente conhecer, poucas realidades podem reduzir-se a elementos puramente visuais, o trabalho do cineasta, qualquer que seja a evolução da tecnologia, deveria consistir precisamente em arrancar ao visivel as predeterminações, os esquemas pré-construídos.

Obviamente não existe uma única via, nem tampouco "alternativas" em sentido estrito. Todavia, na minha opinião, algumas das "lições" do cinema moderno seguem sendo válidas. $O$ trabalho de cineastas como Rosselini, Rouch ou Kiarostami, por exemplo, mostra que é possível uma interpenetração entre realidade e ficção. $\mathbf{E}$ possivel subverter de formas distintas a realidade ou 
erodir as convenções ficcionais mediante, por exemplo, a irrupção de protagonistas que atuem simultaneamente como pessoas e personagens (é o que faz Kiarostami em $A$ vida continua ou Através das oliveiras). Já não se trata, como pretendem as modernas ficções do visível, de "supreender" a vida, e sim de produzir imagens conectadas com a realidade mas com um ligeiro décalage que favoreça a reflexão. Trata-se, em suma, de subverter o reconhecimento, de conseguir que o espectador duvide das imagens plenas, evidentes.

Cada época tem seus realismos, melhor dito, seus efeitos de realidade. A nossa já não trata de conseguir imagens e sons realistas, mas de injetar nas imagens efeitos de realismo, decididamente, de simular o realismo. Como assinala Christian Guillon, diretor do departamento de efeitos especiais digitais da empresa Ex-Machina ${ }^{16}$, as imagens documentais ou das reportagens de atualidade são, antes de tudo, inclusive antes de qualquer intervenção (tecnológica) sobre a imagem, o produto de uma manipulação ${ }^{17}$. O único antítodo contra esse tipo de manipulação é o ceticismo; é necessário criticar a fé absoluta nas imagens e na tecnologia. É preciso conseguir que o espectador saiba que as imagens só falam de si mesmas, em uma palavra, que uma imagem não é mais que uma imagem.

\section{Notas}

1 “Alarme no ciberespaço", Le Monde Diplomatique. setembro de 1996.

2 BAUDRILLARD, Jean.Ocrime perfeito. Barcelona, Anagrama, 1996.

3 Por exemplo: durante o julgamento dos quatro policiais de Los Angeles acusados de espancar um cidadão negro, as imagens do referido espancamento obtidas por um vídeo amador foram utilizadas como provas da defesa e da acusação.

4 Cf. BURCH, N. El tragaluz del infinito, Madrid, Cátedra, 1987.

5 Citado em Jacques Aumont, Oolho interminável, Barcelona, Paidós, 
1997, p. 18.

6 El tragaluz del infinito, op. cit.

7 Iniciando pelo "clássico" de AUERBACH, Mimesis and the representation of reality in western literature, Princeton, University of Princeton Press, 1983; LUKÁCS, G. The meaning of contemporary realism, Londres, Merlin, 1967, ou Writer and critic, Londres, Merlin, 1970; WATT, I. The rise of the novel; Harmondsworth, Penguin, 1957; WILLIAMS, R. "A lecture on realism", in Screen 18:1, p. 61-74.

$8 \mathrm{METZ}, \mathrm{C}$. Essais sur la signification au cinéma. v. 1, Paris, Klincksiek.

9 Não confundir com o cinéma vérité, apesar de tanto um quanto outro proceder dos mesmos avanços técnicos. Grosso modo, a diferença residia em que o cineasta do cinéma direct confiava em encontrar a verdade em decursos acessiveis à câmara, uma câmara observadora e não participante, como a do cinéma vérité. Por outro lado, o cinéma vérité respondia a um paradoxo: as verdades ocultas $s 6$ podem aflorar mediante a criação de situações artificiais; em muitas ocasiōes, o cineasta não se conforma apenas com o observar, mas busca provocar a ação, a crise.

10 MARSOLAIS, G. L'aventure du cinéma direct. Paris, Seghers, 1974.

11 KRAMER, Robert. Biennale Européenne du Documentaire. Marseille, 1991.

12 Publicado em Cahiers du Cinéma. abril, 1991.

13 BAUDRILLARD, Jean. La Guerra del Golfo no ha tenido lugar. Barcelona, Anagrama, 1991.

14 DELEUZE, G. La imagen-tiempo. Barcelona, Paidós, 1987. p. 3637.

15 DELEUZE, G. Op. cit.. p. 37 (o grifo é meu).

16 "Les effets spéciaux et les nouvelles technologies", in Les manipulations de l'image et du son, Paris, Hachette-Fondation pour les Études de Défense, 1996, p. 195-203.

17 O termo "manipulação" é aqui utilizado em sentido amplo, como "manejo" ou "construção". Em nosso campo dita "manipulação" se manifesta em elementos como, por exemplo, o enquadramento ou a montagem.

Tradução de Afonso Henriques de Guimaraens Neto. 